\title{
Commentary: Work harder, not smarter
}

Ashish S. Shah, MD

From the, Department of Cardiac Surgery, Vanderbilt University Medical Center, Nashville, Tenn. Disclosures: Author has nothing to disclose with regard to commercial support.

Received for publication Jan 27, 2019; accepted for publication Jan 28, 2019; available ahead of print March 2, 2019.

Address for reprints: Ashish S. Shah, MD, Vanderbilt University Medical Center, Vanderbilt Medical Center East, 1215 21st Ave S, Suite 5025, Nashville, TN 37232 (E-mail: ashish.s.shah@ vanderbilt.edu).

J Thorac Cardiovasc Surg 2019;158:184-5

$0022-5223 / \$ 36.00$

Copyright (C) 2019 by The American Association for Thoracic Surgery

https://doi.org/10.1016/j.jtcvs.2019.01.099

Improvements in heart transplant outcomes have come in the first year after transplant. Surgical complications and early immunologic events have been mostly overcome. The early postoperative period can be relatively straightforward, with predictable lengths of stay and functional outcomes. Long term outcomes, however, conditional to surviving this period, have not changed significantly in decades.

Recent advances in mechanical circulatory support (MCS) and the rebirth of extracorporeal membrane oxygenation (ECMO), have emboldened teams to start tackling more complex patients. Although reoperations have been a common part of heart transplantation, explanting left ventricular assist devices, total artificial hearts, and paracorporeal systems are another matter entirely. Although surgical teams have made such procedures safe, they are nonetheless technically difficult and exhausting for these teams.

So, reoperations are tough but manageable, and MCS is tough but manageable. In this issue of the Journal, Sanchez and colleagues ${ }^{1}$ have now reported on the US experience with an even more complex group, patients undergoing retransplant while receiving MCS. Retransplantation has been a part of the field for decades, with the general understanding that in patients with chronic graft dysfunction and reasonable renal function, reasonable outcomes are achievable. This, in the setting of a donor heart scarcity, makes some sense. Sanchez and colleagues, ${ }^{1}$ however, report on a group of retransplants done in the setting of preoperative MCS.

The outcomes are surprisingly good in light of the acuity involved; however, patients supported with ECMO fared much worse. Sanchez and colleagues ${ }^{1}$ opine that bridging with ECMO is probably not a good idea.

The report highlights and in many ways is a cautionary tale of how a public trust can be distorted by our care systems. First, the decision to offer retransplant at all is a

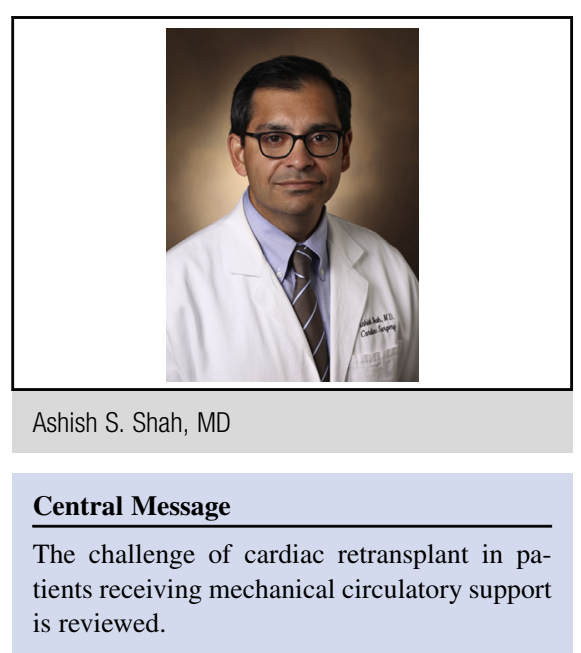

See Article page 171

complex choice that is made by individual institutions rather than the public. The fundamental understanding is that the individual institution is to consider the needs of the many as well as those of their patient. The fact that more than 80 patients have undergone retransplant in this situation, however, suggests that institutions do not really care about the needs of the many. Importantly, more than a third had undergone retransplant within a year of primary transplant. This is an exceptionally high-risk group with known poor outcomes.

Second, the current report adds to growing literature suggesting that ECMO bridging is associated with high early mortality. The new US allocation scheme, however, prioritizes patients with ECMO support relative to others. This could potentially provide an incentive to teams to use ECMO to have access to higher quality organs faster. These are organs that could go to less at-risk patients with better functional results.

Third, the level of disability in the postoperative patients, while not surprising, is nonetheless profound. $90 \%$ of patients require some or total assistance. Whether that persists over time is unknown but certainly given the significant resources involved, is this what our patients expect?

Finally, the cohort is quite small, and the study has perhaps overanalyzed a small group of patients. And although one might conclude that ECMO bridging is futile, it remains a complex decision for the patient, the family, and the public. 
What is clear is that retransplantation is even more complicated with MCS—of any flavor. We will be working much harder to help these patients but not much smarter.

\section{Reference}

1. Sanchez JE, Takayama H, Ando M, Han J, Kurlansky P, Garan AR, et al. Outcomes of cardiac bridge to retransplantation in the contemporary mechanical circulatory support era. J Thorac Cardiovasc Surg. 2019;158:171-81.e1. 